\title{
Activation of a Metabotropic Excitatory Amino Acid Receptor Potentiates Spike-Driven Calcium Increases in Neurons of the Dorsolateral Septum
}

\author{
Fang Zheng, ${ }^{1,3}$ Joel P. Gallagher, ${ }^{2}$ and John A. Connor ${ }^{1,4}$ \\ ${ }^{1}$ Roche Institute of Molecular Biology, Nutley, New Jersey 07110-1199, 2Department of Pharmacology and Toxicology, \\ University of Texas Medical Branch, Galveston, Texas 77555-1031, 32Department of Pharmacology, Emory University \\ School of Medicine, Atlanta, Georgia 30322, and ${ }^{4}$ The Lovelace Institute, Albuquerque, New Mexico 87105
}

(1S,3R)-1-aminocyclopentane-1,3-dicarboxylic acid (1S,3RACPD), an agonist for metabotropic glutamate receptors (mGluRs), causes depolarization and burst firing in rat dorsolateral septal nucleus (DLSN) neurons and results in long-term potentiation (LTP) at DLSN synapses. In the present study, we investigated whether these actions of 1S,3R-ACPD are attributable to the release of calcium from an inositol triphosphatesensitive store after activation of mGluRs coupled to phospholipase C. Our data demonstrated that the ACPD-induced depolarization was associated with a small but significant decrease, not an increase, in $\left[\mathrm{Ca}^{2+}\right]_{i}$; however, changes of $\left[\mathrm{Ca}^{2+}\right]_{i}$ during ACPD-induced bursting were up to seven times larger than those produced by regular firing. Depletion of internal calcium stores by thapsigargin or ryanodine had a small to insignificant effect on the maximum changes of $\left[\mathrm{Ca}^{2+}\right]_{i}$ associated with ACPD-induced bursting. Thus, elevation of $\left[\mathrm{Ca}^{2+}\right]_{\mathrm{i}}$ during firing by $1 \mathrm{~S}, 3 \mathrm{R}-\mathrm{ACPD}$ is likely attributable to enhancement of calcium influx through voltage-gated channels and not to calcium release from internal stores. ACPD-induced burst firing elevated somatic and dendritic calcium levels up to 3 and $6 \mu \mathrm{M}$, respectively. Such an increase may be the underlying mechanism for ACPD-induced LTP as well as ACPD-induced acute cell death in rat DLSN.

Key words: metabotropic glutamate receptors; intracellular calcium; long-term potentiation; neurotoxicity; thapsigargin; ryanodine; voltage-gated calcium channels
Molecular studies have revealed two families of excitatory amino acid receptors, i.e., "ionotropic" and "metabotropic" receptors. Eight metabotropic glutamate receptors (mGluRs) have been cloned to date and are classified into three major groups on the basis of sequence homology, coupling to second messenger systems, and selectivity for various agonists (Pin and Duvoisin, 1995). Accumulating data suggest that mGluRs have a significant role in many physiological and pathological processes (Conn et al., 1994; Gallagher et al., 1994; Gerber and Gahweiler, 1994). One possible functional role of group I mGluRs (mGluR1 and 5), which couple primarily to phospholipase C, may be their involvement in learning and memory. Deficiencies in context-specific associative learning and motor learning have been observed in mGluR1-deficient transgenic mice (Aiba et al., 1994a,b). (1S,3R)-1-aminocyclopentane-1,3-dicarboxylic acid (1S,3R-ACPD), an agonist of mGluRs, induces LTP in the hippocampus (Bortolotto and Collingridge, 1993), the olfactory cortex (Collins, 1994), and the dorsolateral septal nucleus (DLSN) (Zheng and Gallagher, 1992c), which possesses the highest density of group I mGluRs in the brain (Cha et al., 1990).

The septum, a major limbic relay nucleus, is involved in learning and the generation of "theta rhythm" (Gallagher et al., 1995). Because long-term potentiation (LTP) can be induced without activation of NMDA receptors at DLSN synapses, the rat DLSN provides a powerful model for investigating the intracellular sig-

Received Jan. 23, 1996; revised July 2, 1996; accepted July 9, 1996.

This work was supported in part by a J. E. Kempner Fellowship (F.Z.) and by National Institute of Mental Health Grant MH 39163 (J.P.G.).

Correspondence should be addressed to Dr. Fang Zheng, Department of Pharmacology, Emory University School of Medicine, 1510 Clifton Road, Atlanta, GA 30322.

Copyright (C) 1996 Society for Neuroscience $0270-6474 / 96 / 166079-10 \$ 05.00 / 0$ naling pathway for the induction mechanism of mGluRdependent LTP. Thapsigargin, which depletes internal calcium stores (Thastrup et al., 1990), blocked the induction of LTP at DLSN synapses (Zheng and Gallagher, 1992d). Thus, 1S,3RACPD may raise $\left[\mathrm{Ca}^{2+}\right]_{\mathrm{i}}$ for LTP induction by releasing calcium from internal calcium stores. Such release has been observed in Purkinje neurons in cerebellum (Linden et al., 1994), pyramidal neurons in hippocampus (Jaffe and Brown, 1994), and neurons of the cochlear nucleus (Zirpel et al., 1995), and has often been considered as a possible contributing factor to LTP induction. Our biochemical study (Zheng et al., 1994) demonstrated that 1S,3RACPD raised inositol triphosphate $\left(\mathrm{IP}_{3}\right)$ levels in DLSN slices only at concentrations higher than $30 \mu \mathrm{M}$. It remains uncertain whether 1S,3R-ACPD could cause significant calcium release from $\mathrm{IP}_{3}$-sensitive stores at concentrations used to induce LTP $(10-20 \mu \mathrm{M})$. Another possible pathway by which ACPD could elevate $\left[\mathrm{Ca}^{2+}\right]_{\mathrm{i}}$ is enhancement of calcium influx. We have demonstrated that $1 \mathrm{~S}, 3 \mathrm{R}-\mathrm{ACPD}$ caused membrane depolarization, burst firing, and potentiation of the slow afterdepolarization (Zheng and Gallagher, 1991, 1992a,b). ACPD could directly potentiate voltage-gated calcium channels, or, alternatively, activation of calcium-activated nonselective (CAN) channels would bring in additional calcium if they are calcium permeable. The mechanism by which $\left[\mathrm{Ca}^{2+}\right]_{i}$ is raised to trigger mGluRdependent LTP at the DLSN synapses remains unclear and needs to be elucidated.

In this study, we investigated with fluorescent calcium indicators the effects of $1 \mathrm{~S}, 3 \mathrm{R}-\mathrm{ACPD}$ on $\left[\mathrm{Ca}^{2+}\right]_{\mathrm{i}}$ of DLSN neurons. Our data show that $1 \mathrm{~S}, 3 \mathrm{R}-\mathrm{ACPD}$ does not cause any significant release of calcium from internal stores but greatly potentiates spikedriven calcium increases by approximately sevenfold. Such an 

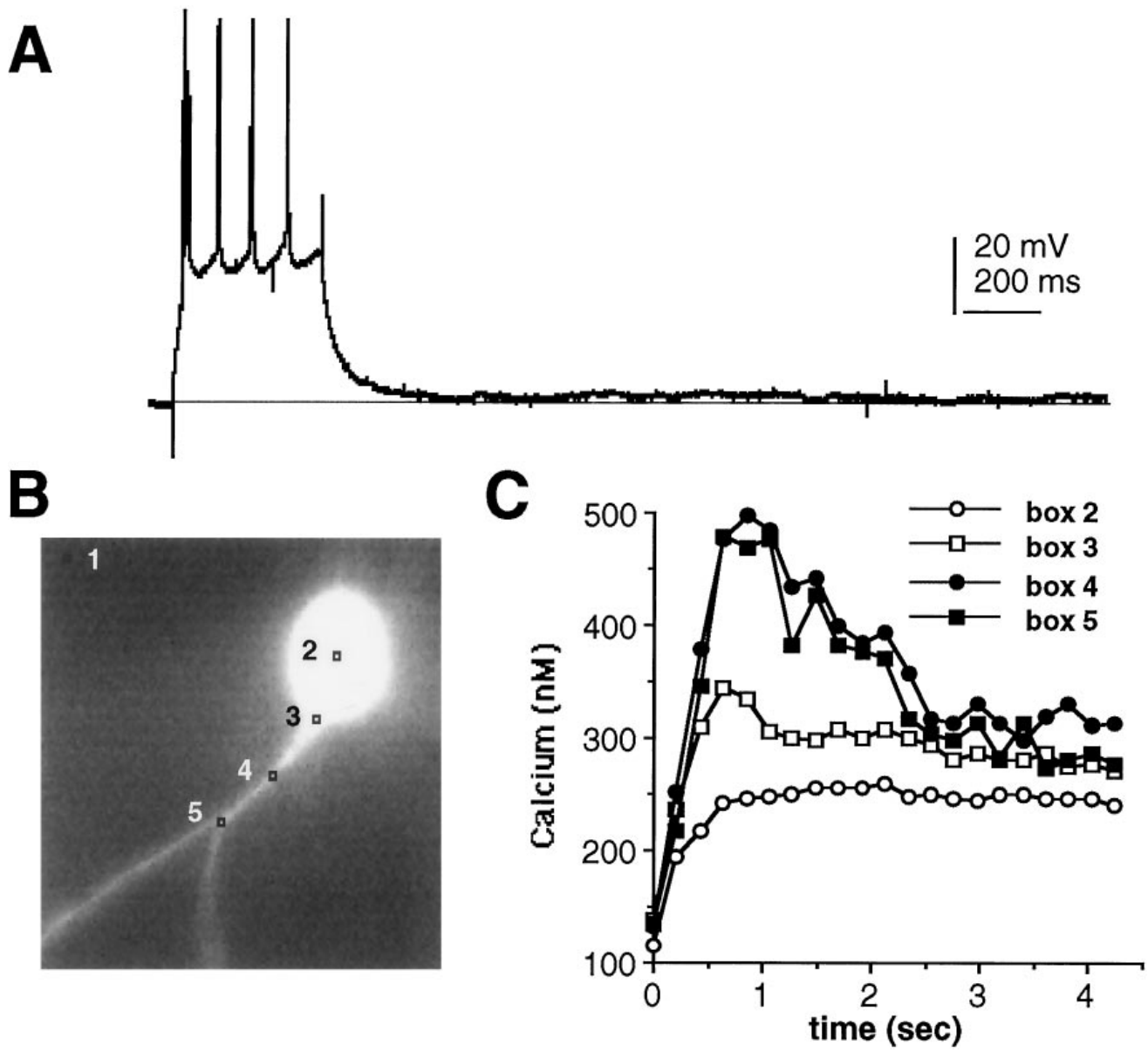

Figure 1. Calcium homeostasis of DLSN neurons. $A$, Spike train elicited by a depolarizing current pulse $(0.2 \mathrm{nA}, 400 \mathrm{msec})$. Membrane potential was held at $-80 \mathrm{mV}$. B , Fluorescence image of this DLSN neuron, $380 \mathrm{~nm}$ excitation. Analysis locations are indicated by $3 \times 3$ pixel square boxes. Each pixel subtends an area of $\sim 0.5 \times 0.5 \mu \mathrm{m}$. Box 1 is used as background to correct the 350/380 ratio measured at box 2-5. C, Calcium increases in soma and dendrites caused by firing are shown in $A$.

increase may be responsible for ACPD-induced LTP and possibly could initiate ACPD-induced acute death of DLSN neurons.

\section{MATERIALS AND METHODS}

\section{Preparation of septal slice}

Rat forebrain coronal slices containing septal nucleus were obtained in a manner described previously (Stevens et al., 1984). In brief, male Sprague-Dawley rats (Holtzman, 90-150 gm) were decapitated, and the brains were removed rapidly and cut into serial transverse sections (300 $\mu \mathrm{m}$ thick) with a D.S.K. Microslicer (DTK-200) in a modified ice-cold artificial CSF (ACSF), which was bubbled continuously with $95 \% \mathrm{O}_{2} / 5 \%$ $\mathrm{CO}_{2}$ to maintain $\mathrm{pH}$ at 7.3-7.4. A septal slice was submerged in our recording chamber and superfused with gassed ACSF at a rate of 1-2 $\mathrm{ml} / \mathrm{min}$. The recording chamber was heated to maintain an experimental temperature of $32 \pm 1{ }^{\circ} \mathrm{C}$. The composition of the modified ACSF was (in $\mathrm{mm}$ ): $117 \mathrm{NaCl}, 4.7 \mathrm{KCl}, 1.2 \mathrm{NaH}_{2} \mathrm{PO} 4,2.5 \mathrm{CaCl}_{2}, 25 \mathrm{NaHCO}_{3}, 1.2$ $\mathrm{MgCl}_{2}$, and 11.5 glucose.

Simultaneous electrophysiological recording and digital optical imaging of cytosolic calcium

Standard intracellular recording. Microelectrodes were pulled from filamented capillary glass (standard wall, $1.0 \mathrm{~mm}$ outer diameter; Sutter Instrument, Novato, CA) on a Flaming Brown Micropipette Puller (Model P-87/PC) to a final tip resistance of $60-90 \mathrm{M} \Omega$ and filled with $2 \mathrm{M} \mathrm{KCl}$. Voltage signals and applied current were recorded with an Axon Instruments (Foster City, CA) Axoclamp 2A amplifier and displayed on an analog oscilloscope. The amplified voltage and current responses were recorded on videotape and recorded simultaneously on a two-channel Gould Model 220 chart recorder.
Calcium imaging techniques. For calcium imaging, DLSN neurons were impaled with electrodes filled with $10 \mathrm{~mm}$ Fura- 2 or $20 \mathrm{~mm} \mathrm{Mg}$-Fura-5 (in $1 \mathrm{M} \mathrm{KCl}$ solution) in the tip and then backfilled with $2 \mathrm{M} \mathrm{KCl}$, as described previously (Petrozzino et al., 1995). All experiments were conducted at least $30 \mathrm{~min}$ after initial impalement to allow stabilization of fluorescent

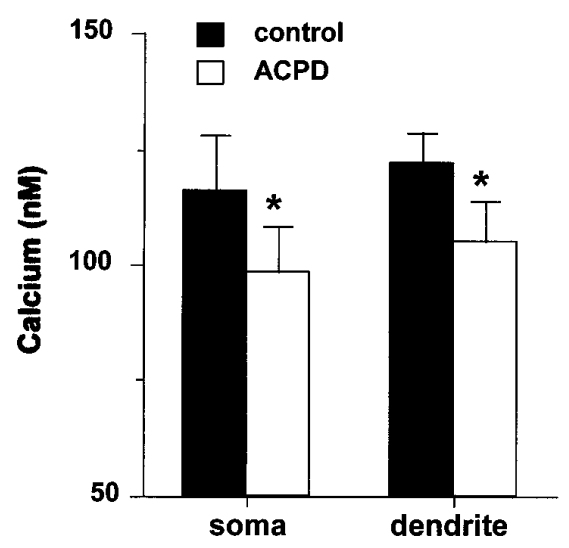

Figure 2. ACPD reduces baseline calcium levels. Changes of baseline $\left[\mathrm{Ca}^{2+}\right]_{\mathrm{i}}$ associated with depolarization induced by $20 \mu \mathrm{M}$ 1S,3R-ACPD in DLSN neurons $(n=8)$. Note that the calcium levels were reduced in both the soma and the dendrites. Asterisk indicates statistical significance $(p<$ 0.05 ; paired $t$ test). 
A

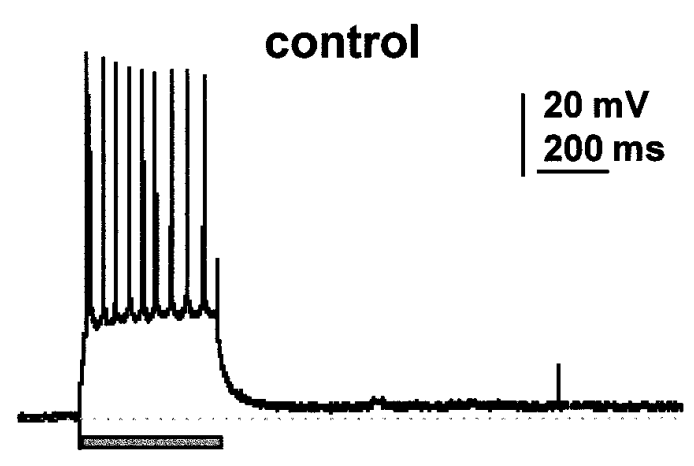

B

ACPD

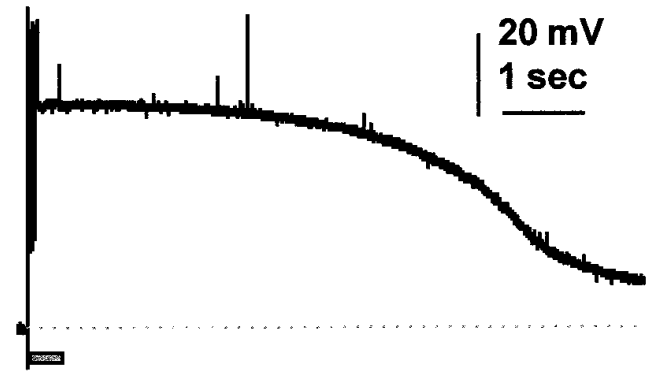

C

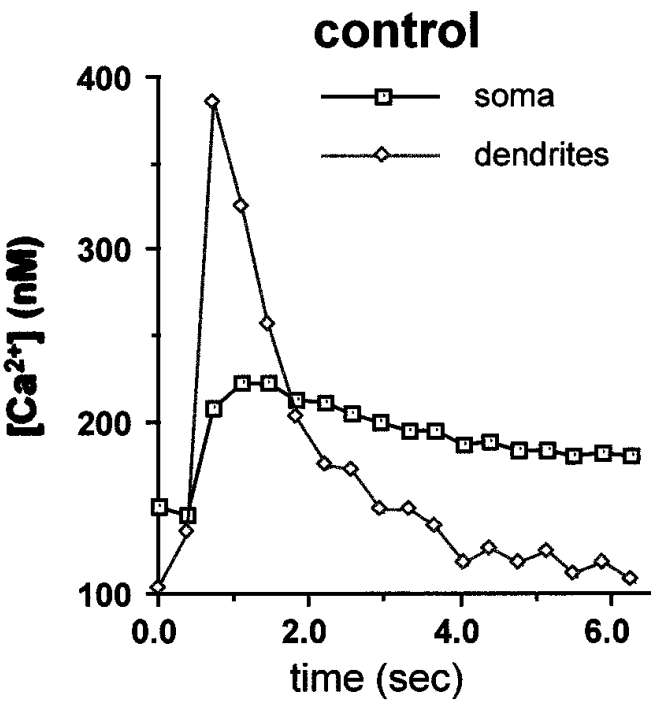

E

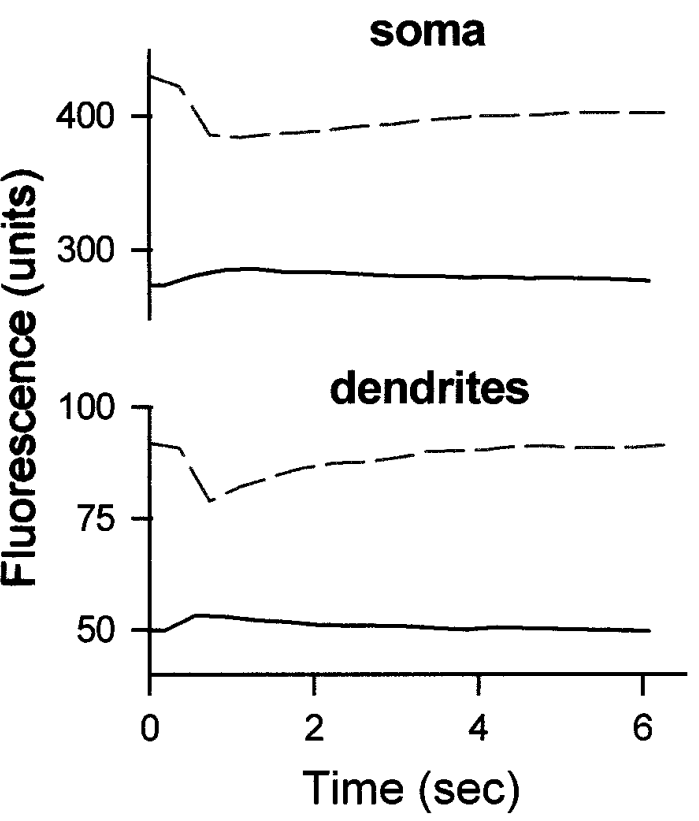

D

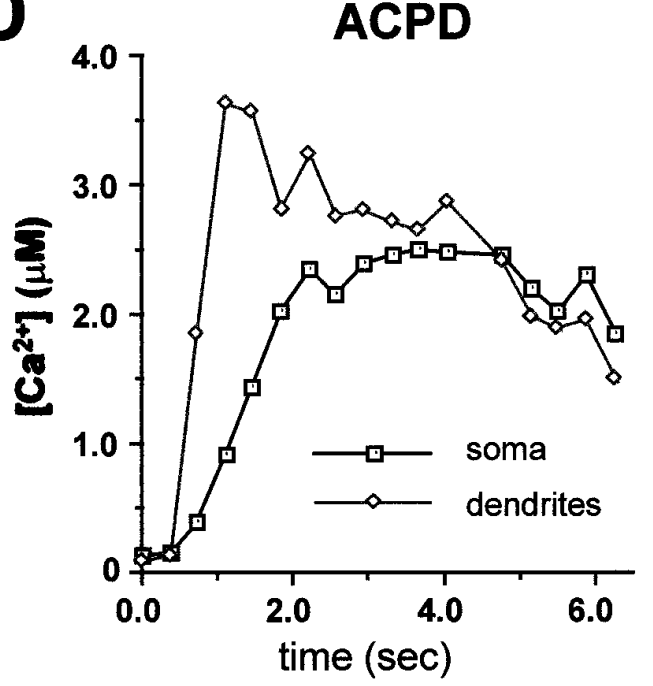

F

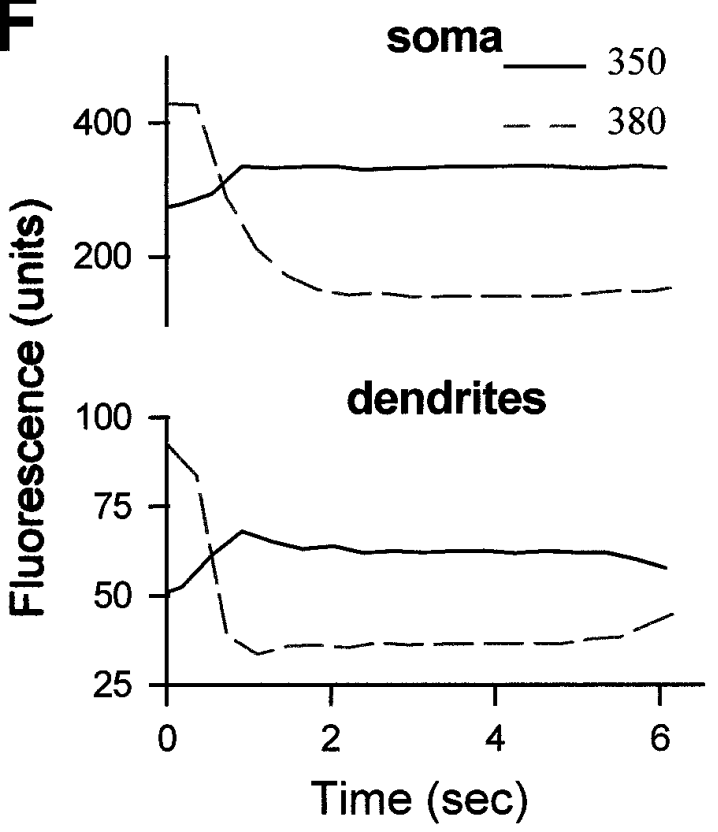

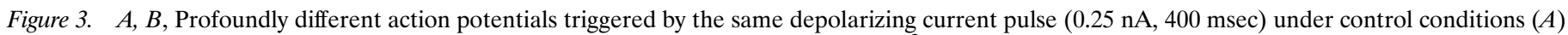

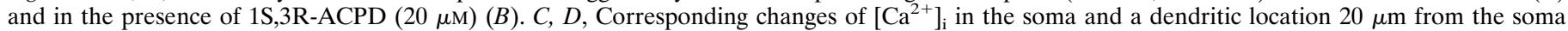
are shown in the panels below each voltage trace. Membrane potential was held at $-79 \mathrm{mV}$. 


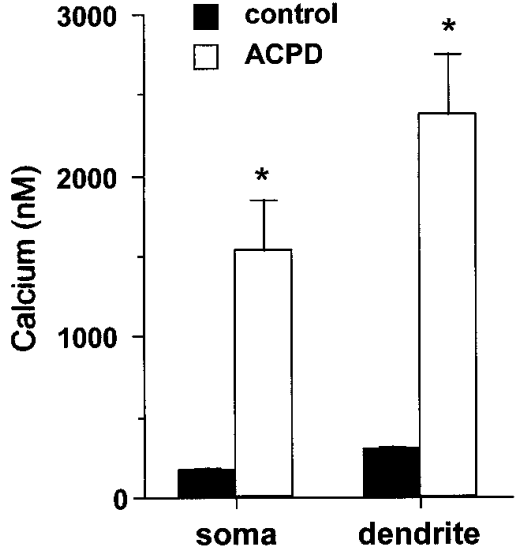

Figure 4. ACPD enhances spike-triggered calcium influx. Peaks of $\left[\mathrm{Ca}^{2+}\right]_{\mathrm{i}}$ in soma and dendrites associated with regular firing and ACPDinduced bursting in DLSN neurons $(n=16)$. Note that the peak values of calcium during ACPD-induced bursting are far greater than those associated with regular firing. Asterisk indicates statistical significance $(p<0.05$; paired $t$ test).

signals. Indicator fluorescence was elicited by epi-illumination with light from a mercury arc lamp, split, passed through separate 350 and $380 \mathrm{~nm}$ filters, and recombined to form two shutter-controlled ultraviolet light sources. DLSN neurons were imaged from the top surface of the slices using an upright microscope (Zeiss Axioskop) and a long working distance, water-immersion $40 \times$ objective (Zeiss, NA 0.75). A CCD camera system (Photometrics, Tucson, AZ), controlled by an accelerated Macintosh II computer, was used in the frame-transfer mode to acquire paired images at 350 and $380 \mathrm{~nm}$ excitation wavelengths. A logic signal from the camera controller served as a trigger to synchronize image acquisition with delivery of the depolarizing current pulse used to evoke firing. Cytosolic $\left[\mathrm{Ca}^{2+}\right]$ was determined from background-corrected image pairs using the ratio methods, as described previously (Grynkiewicz et al., 1985; Tsien and Poenie, 1986), and measurements are reported as such. Individual wavelength changes ( 350 and $380 \mathrm{~nm}$ excitation) were always checked, and a reported $\left[\mathrm{Ca}^{2+}\right]$ increase implies an increase in the 350 $\mathrm{nm}$ excited fluorescence concurrent with a decreased 380 excited signal (see Fig. $3 E, F$ ). Analysis regions consisted of a $3 \times 3$ or $3 \times 5$ pixel area. Calcium signals from only soma and primary dendrites have been analyzed here. Secondary dendrites of DLSN neurons are very thin, and we could not routinely obtain adequate fluorescent signals from these dendrites. $K_{\mathrm{d}}$ for Mg-Fura-5 was determined as described previously (Petrozzino et al., 1995). Pharmacological agents were superfused at the nominal concentrations. To ensure equilibrium conditions, antagonists were superfused for a minimum of $10 \mathrm{~min}$ before testing of an agonist. Bicuculline methiodide ( $25 \mu \mathrm{M}$; Sigma, St. Louis, MO) and D,L-2-amino5 -phosphonovalerate (AP5) (50 $\mu \mathrm{M}$, Sigma) were used routinely to block $\mathrm{GABA}_{\mathrm{A}}$ and NMDA receptors, respectively. 1S,3R-ACPD was purchased from Tocris Cookson. Fura-2 and Mg-Fura-5 were purchased from Molecular Probes (Eugene, OR).

\section{RESULTS}

\section{Calcium homeostasis of DLSN neurons}

DLSN neurons have been classified into "bursters" and "nonbursters" on the basis of their intrinsic membrane properties and their firing patterns (Gallagher et al., 1995). Bursters are a small subpopulation of DLSN neurons that have a burst-type firing pattern and exhibit a slow afterdepolarizaton (sADP) mediated by a CAN current (Hasuo et al., 1990). A large majority of DLSN neurons $(85 \%)$ are nonbursters, which fire randomly and do not exhibit an sADP. In the present study, 27 DLSN neurons near the surface of slices were impaled with sharp microelectrodes, and the fluorescent calcium indicator Fura-2 was injected. Twenty-five of the 27 DLSN neurons were nonbursters, a percentage consistent with our previous experience (Zheng and Gallagher, 1995a).
Measures of basal calcium levels of DLSN nonburster neurons $(n=25)$ were between 54 and $169 \mathrm{~nm}$ in the soma and between 32 and $137 \mathrm{~nm}$ in the dendrites, with an average of $110 \pm 8$ and $100 \pm$ $7 \mathrm{~nm}$, respectively. We observed higher basal calcium levels in the soma (146 and $149 \mathrm{~nm}$ ) than in the dendrites (95 and $103 \mathrm{~nm}$ ) of the two DLSN burster neurons.

To investigate calcium homeostasis, depolarizing current pulses (400 msec) were used to trigger firing and generate calcium influx. Figure $1 A$ shows a typical action potential trace, and $1 C$ shows the resulting calcium changes at four locations in the soma and dendrites. Figure $1 B$ gives the measurement locations. In the primary dendrite, the calcium increase generally reached its peak near the end of the depolarizing current pulse, with soma levels climbing more slowly (also see Fig. 3). Full recovery to resting levels required $\sim 20 \mathrm{sec}$. The peak value of dendritic calcium increases was $288.6 \pm 22.1 \mathrm{nM}$, which is significantly greater than the peak calcium levels $(172.6 \pm 11.8 \mathrm{~nm})$ in the soma of DLSN neurons $(n=16$; paired $t$ test; $p<0.01)$.

\section{ACPD-induced depolarization is associated with a decrease in $\left[\mathrm{Ca}^{2+}\right]_{\mathrm{i}}$ of DLSN neurons}

We have reported previously that 1 S,3R-ACPD caused a depolarization of DLSN neurons accompanied by an increase of membrane conductance and burst firing. It is possible that this depolarization occurs because calcium released from internal stores by 1S,3R-ACPD activates an inward membrane current such as a CAN current. Neurons were held at $-80 \mathrm{mV}$ and bathed in bicuculline and AP5 to block $\mathrm{GABA}_{\mathrm{A}}$ and NMDA receptors. In some cases, depolarization caused by $1 \mathrm{~S}, 3 \mathrm{R}$-ACPD was compensated manually by applying an outward current so that spontaneous firing was avoided. In 7 of 10 neurons, $\left[\mathrm{Ca}^{2+}\right]_{\mathrm{i}}$ in the dendrites and soma were both reduced while the neurons were being depolarized by $1 \mathrm{~S}, 3 \mathrm{R}-\mathrm{ACPD}(10-50 \mu \mathrm{M})$. A particular example is depicted graphically and with false color mapping in Figure 5, $A a$ and $A b$. In two neurons, the $\left[\mathrm{Ca}^{2+}\right]_{\mathrm{i}}$ in dendrites became oscillatory, whereas the $\left[\mathrm{Ca}^{2+}\right]_{\mathrm{i}}$ in the soma was reduced. The range of dendritic calcium oscillation in these two neurons is $65-170 \mathrm{~nm}$. A small calcium increase $(10 \%)$ was observed in both soma and primary dendrites of one neuron. On average, $\left[\mathrm{Ca}^{2+}\right]_{\mathrm{i}}$ in soma was reduced from $116 \pm 12$ to $98 \pm 10 \mathrm{nM}$, whereas $\left[\mathrm{Ca}^{2+}\right]_{\mathrm{i}}$ in dendrites was reduced from $122 \pm 6$ to $105 \pm 8 \mathrm{~nm}$ (see Fig. 2). When the changes of $\left[\mathrm{Ca}^{2+}\right]_{i}$ were normalized, 1S,3R-ACPD reduced $\left[\mathrm{Ca}^{2+}\right]_{\mathrm{i}}$ in soma and dendrites to $84.8 \pm 3.3$ and $85.7 \pm$ $4.0 \%$ of control levels, respectively. Although these reductions were small, they were significant ( $n=8 ; p<0.05$; paired $t$ test). These observations indicated that $1 \mathrm{~S}, 3 \mathrm{R}-\mathrm{ACPD}$, at a concentration $(20 \mu \mathrm{M})$ that induces LTP at rat DLSN, did not trigger calcium release from internal stores in the majority of neurons and that the inward current activated by ACPD carried very little calcium.

\section{S,3R-ACPD greatly potentiates spike-triggered increase of $\left[\mathrm{Ca}^{2+}\right]_{\mathrm{i}}$ in DLSN neurons}

In neurons loaded with Fura-2 $(n=16), 1 \mathrm{~S}, 3 \mathrm{R}-\mathrm{ACPD}$ caused the transition from tonic firing in response to current stimulus to extended burst firing (as shown in Fig. $3 A, B$ ) identical to that described previously (Zheng and Gallagher, 1991, 1992a). Depolarization caused by 1S,3R-ACPD (as depicted in Fig. 5Aa) frequently led to spontaneous burst discharge; however, we analyzed only data from evoked bursts synchronized with the optical data. Calcium increases associated with the normal firing and with the ACPD-induced burst are shown for a 

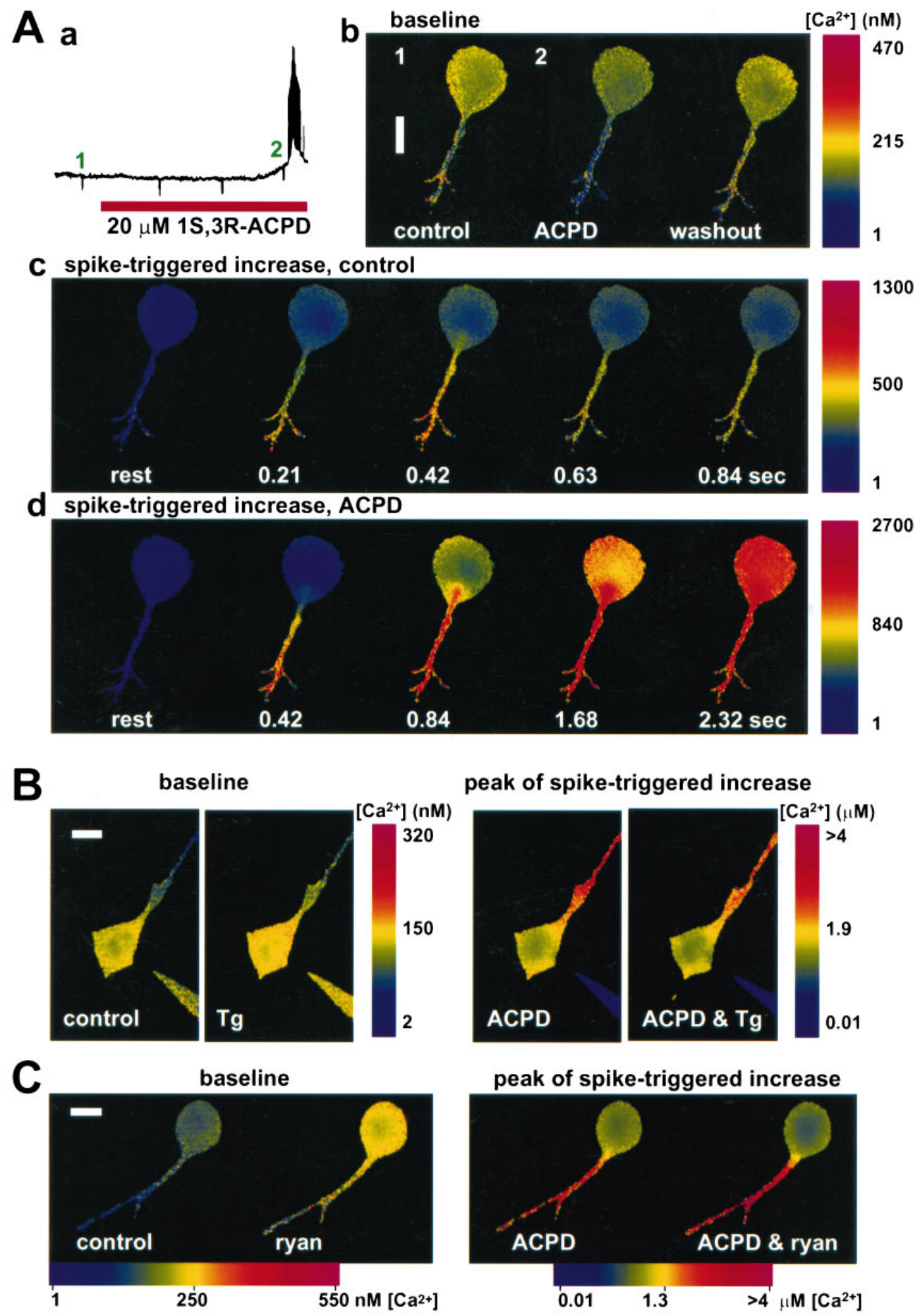

Figure 5. A, Effects of ACPD on $\left[\mathrm{Ca}^{2+}\right]_{\mathrm{i}}$ in DLSN neurons. Aa, Continuous voltage trace showing the membrane depolarization produced by 1S,3R-ACPD (20 $\mu \mathrm{M}) . A b$, False color maps of calcium levels in this neuron. Control levels were measured at point 1 in $a$, and ACPD levels were measured at point 2 , when the slow depolarization was near maximal but before firing began. $A c$, False color map showing spike-triggered calcium increases in the dendrites and soma of a DLSN neuron under control conditions. A train of sodium spikes was generated by a depolarizing current pulse $(0.25 \mathrm{nA}, 400 \mathrm{msec})$ as in Figures 1 and 3. $A d$, Calcium changes evoked by the identical current stimulus in the presence of $1 \mathrm{~S}, 3 \mathrm{R}-\mathrm{ACPD}(20 \mu \mathrm{M})$. In both $A c$ and $A d$, images were acquired at the times indicated after the onset of the depolarizing current pulse. Note change in the range of color bars among $b, c$, and $d$. Scale bar, $10 \mu \mathrm{m} . B, C$, Effects of thapsigargin $(T g)$ and ryanodine (ryan). Thapsigargin $(5 \mu \mathrm{M})$ caused a small increase in baseline calcium levels in both soma and dendrites. It also reduced the peak of calcium increases caused by ACPD-induced bursting. Ryanodine (100 $\mu \mathrm{M})$ increased basal calcium levels in both soma and dendrites; however, it did not alter the peak of calcium increases caused by ACPD-induced bursting. Note change in the range of color bars for the baseline (left) and spike-triggered calcium changes (right). Scale bar, $10 \mu \mathrm{m}$. 

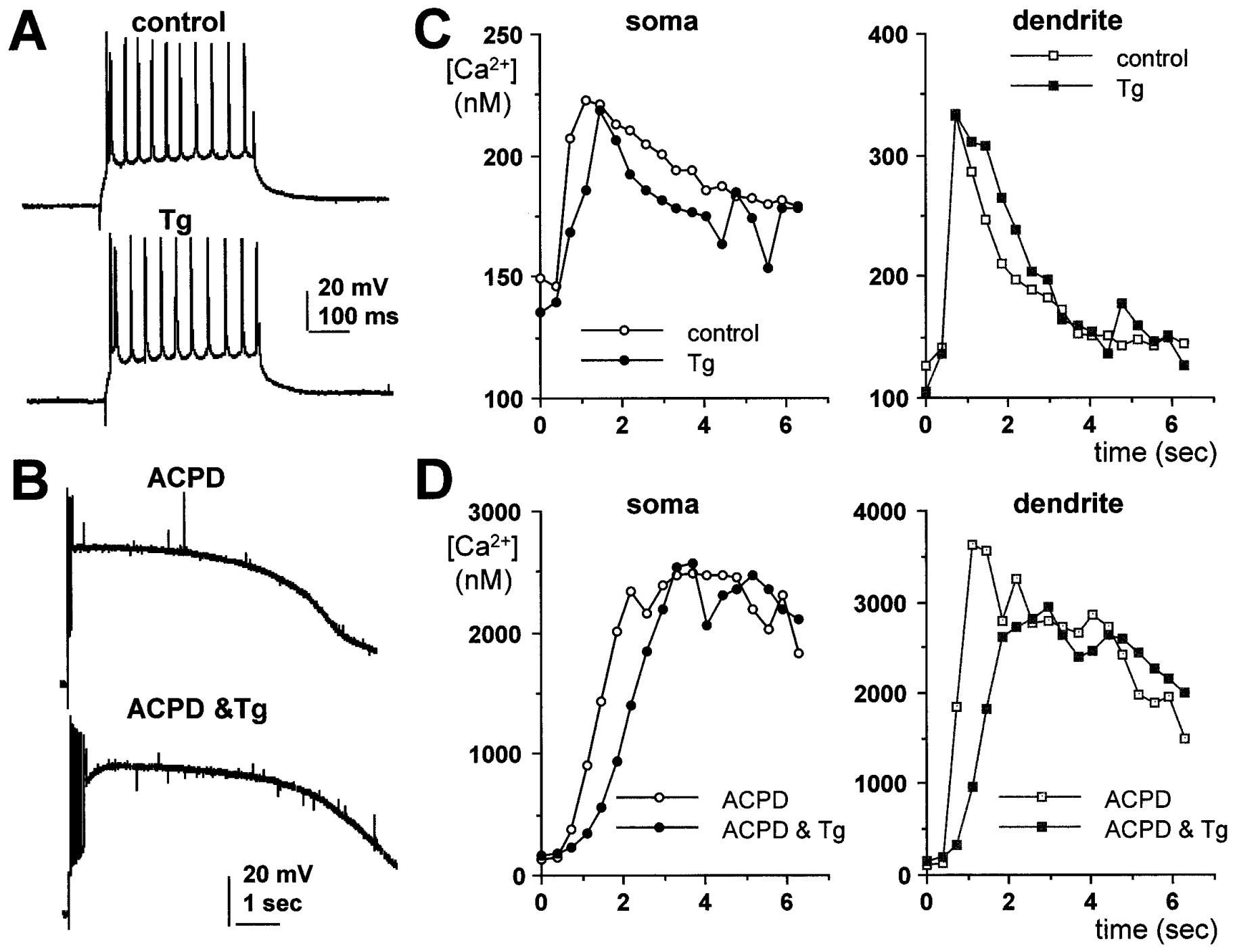

Figure 6. Effects of thapsigargin on firing and changes of $\left[\mathrm{Ca}^{2+}\right]_{\mathrm{i}}$ associated with firing in DLSN neurons. Thapsigargin $(\mathrm{Tg})(5 \mu \mathrm{M})$ had no effects on firing by itself $(A)$; however, it delayed the onset of the ACPD-induced plateau potential but did not reduce the duration $(B)$. $C$ and $D$ show the associated calcium changes in the same neuron. Thapsigargin had little effect on calcium changes caused by normal firing $(C)$, but it reduced the peak calcium increases caused by ACPD-induced bursting $(D)$. Membrane potential was held at $-79 \mathrm{mV}$. A depolarizing current pulse $(0.25 \mathrm{nA}, 400 \mathrm{msec})$ was applied to trigger firing in all cases.

dendritic and soma location in Figure 3, $C$ and $D$. Figure 3, E and $F$, showed the corresponding 350/380 fluorescence. The maximum calcium levels were increased by nearly 10 -fold over control after exposure to ACPD. In this neuron the dendritic calcium both increased and recovered more rapidly than the level in the soma, in contrast to the neuron of Figure 1 in which the late phase of recovery was similar in both soma and dendrite. Comparison of calcium changes in control and ACPD $(20 \mu \mathrm{M})$ is shown in Figure 4.

Figure 5, $A c$ and $A d$, illustrates the spatial characteristics of the calcium changes using false color mapping. The largest changes were apparent first in the distal dendrites. This is especially apparent in the ACPD records (e.g., $t=0.42 \mathrm{sec}$ ), in which a substantial gradient exists down a structure of rather uniform diameter. The contribution of the small surface-to-volume ratio of the soma toward shaping the response profile, relative to other possible factors such as density of calcium entry or release sites, is unclear at this time. The dendritic calcium levels reached their peak at the beginning of the plateau depolarizing potential, whereas somatic calcium levels reached their peak approximately at the middle point of the plateau potentials (Fig. 3B,D). On average, the peak values of $\left[\mathrm{Ca}^{2+}\right]_{\mathrm{i}}$ resulting from firing increased from $173 \pm 12 \mathrm{~nm}$ in control saline to $1.5 \pm 0.3 \mu \mathrm{M}$ in ACPD in the soma and from $289 \pm 22$ to $2.4 \pm 0.4 \mu \mathrm{M}$ in the dendrites (Fig. 4). When calcium changes were normalized, the peak values of $\left[\mathrm{Ca}^{2+}\right]_{\mathrm{i}}$ in soma and dendrites were increased by $6.6 \pm 1.5$ - and $7.3 \pm 1.3$-fold, respectively.

We also observed a refractory period after each episode of bursting. A second depolarizing current pulse, applied immediately after the bursting induced by the first current pulse, evoked only regular sodium spikes, not a burst. Under such circumstances $(n=4)$, the spike-triggered calcium increases in soma and dendrites were not different from control values (i.e., $104 \pm 6$ and $97 \pm 2 \%$ of control values, respectively).

We were able to measure calcium changes associated with ACPD-induced bursting in secondary dendrites in two DLSN neurons. These measurements indicated no significant differences between the calcium changes in primary and secondary dendrites. 

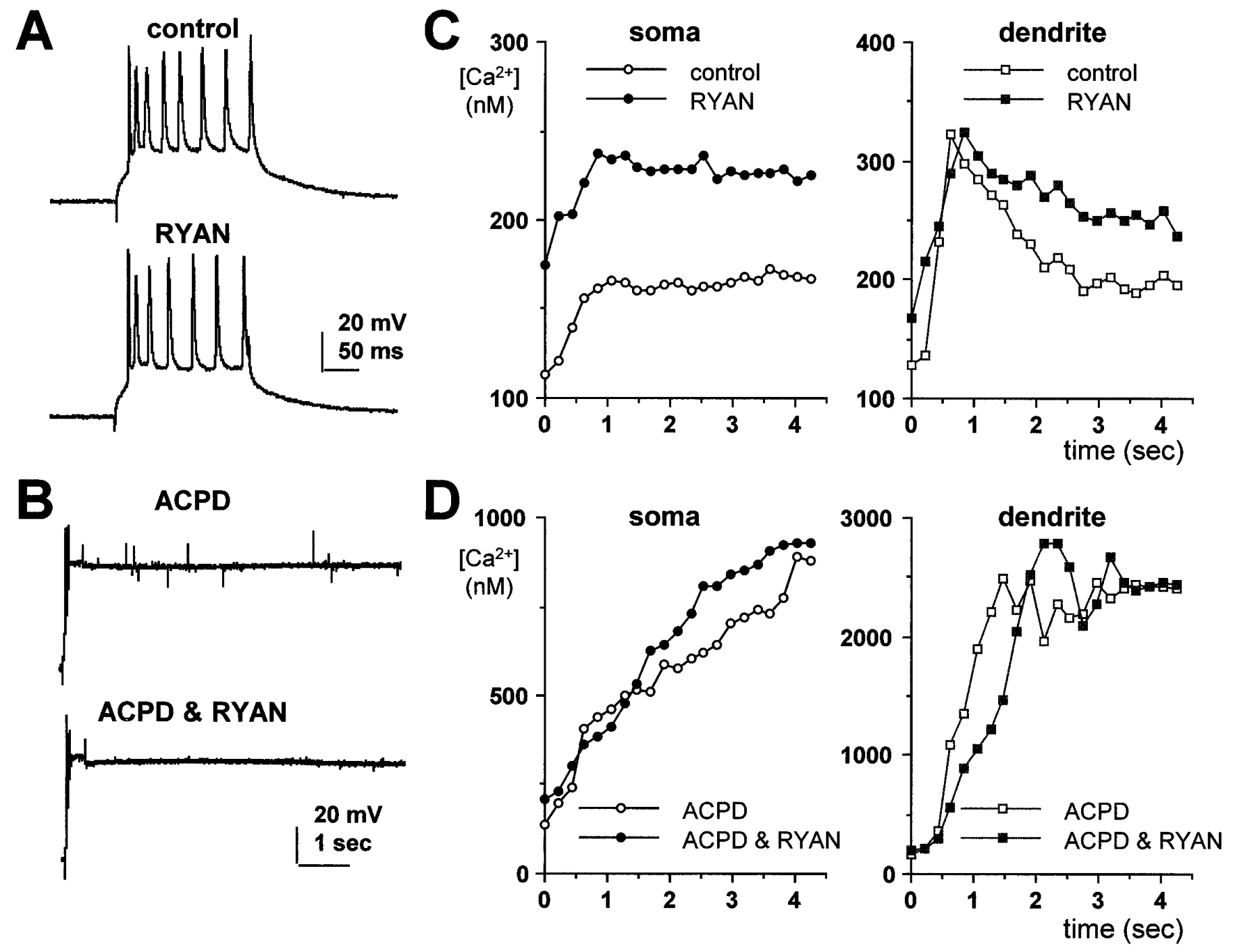

Figure 7. Effects of ryanodine on firing and changes of $\left[\mathrm{Ca}^{2+}\right]_{\mathrm{i}}$ associated with firing in DLSN neurons. Ryanodine $(R Y A N)(100 \mu \mathrm{M})$ had no effect on normal firing $(A)$ or ACPD-induced bursting $(B)$. $C$ and $D$ show the calcium changes caused by firing shown in $A$ and $B$, respectively. Ryanodine markedly slowed the recovery of calcium to baseline after normal firing without affecting the peak level reached $(C)$. It also had little effect on the magnitude of calcium changes caused by ACPD-induced bursting $(D)$. Recovery of $\left[\mathrm{Ca}^{2+}\right]_{\mathrm{i}}$ was not assessed after this unusually long bursting. Membrane potential was held at $-78 \mathrm{mV}$. A depolarizing current pulse $(0.25 \mathrm{nA}, 400 \mathrm{msec})$ was applied to trigger firing.

\section{Disruption of internal stores has different effects on calcium changes in soma and dendrites}

We have demonstrated that calcium increases associated with ACPD-induced bursting are far greater than calcium increases caused by regular firing. A majority of calcium may come from the extracellular space, because the calcium levels were linked to the plateau potential observed during ACPD-induced bursting. Calcium release from internal stores may contribute significantly, however, even though 1S,3R-ACPD by itself did not generally cause calcium increases. To investigate the possible contribution of calcium release from internal stores to calcium increases associated with either regular firing or ACPD-induced bursting, we pretreated septal slices with thapsigargin $(5 \mu \mathrm{M})$, which depletes endoplasmic stores by blocking calcium reuptake (Thastrup et al., 1990). Thapsigargin, at the concentration used in this study, blocks the induction of LTP in hippocampus (Bortolotto and Collingridge, 1993), olfactory cortex (Collins, 1994), and DLSN (Zheng and Gallagher, 1992d). The specificity of thapsigargin as a pure blocker of endoplasmic calcium ATPase has been ques- tioned recently because it blocks calcium currents in some neurons (Nelson et al., 1994; Shmigol et al., 1995).

In three of seven DLSN neurons, thapsigargin caused a significant, transient increase of baseline $\left[\mathrm{Ca}^{2+}\right]_{\mathrm{i}}$ in soma and dendrites, ranging from 20 to $50 \%$ of baseline levels, as depicted in Figure $5 B$. In two DLSN neurons, the basal calcium levels became oscillatory after treatment with thapsigargin. In the remaining two DLSN neurons, no detectable changes occurred.

Thapsigargin has no detectable effects on firing of DLSN neurons (Fig. 6A). It also had little effect on maximum calcium changes associated with firing, as shown in Figure $6 C$. On average, the peaks of spike-triggered calcium increase in the presence of thapsigargin $(n=4)$ were $101 \pm 1$ and $108 \pm 5 \%$ of peak increases under control conditions in the soma and dendrites, respectively. We did not observe a $20-50 \%$ reduction of calcium peaks by thapsigargin shown in cortical neurons (Markram et al., 1995). Thus, it is unlikely that thapsigargin inhibits calcium channels in DLSN neurons. Thapsigargin had only a minor effect on the maximum somatic calcium increases associated with the 


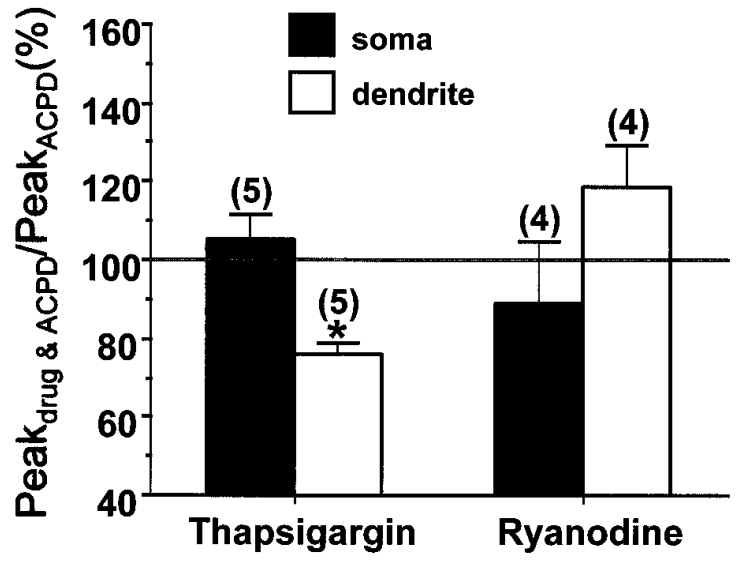

Figure 8. Thapsigargin selectively reduced dendritic calcium increases associated with ACPD-induced bursting in DLSN neurons. The peaks of calcium increases associated with ACPD-induced bursting were measured in the absence or presence of thapsigargin or ryanodine, and the ratio is calculated. Ratios from different neurons were pooled and averaged. Paired $t$ test was used to determine the statistical significance.

ACPD-induced burst (see Figs. $5 B, 6 D, 8$ ); however, it reduced the peak increases in dendrites (Figs. $5 B, 6 D, 8)$ by $23 \pm 3 \%(n=$ 5 ). The rate of rise of both the soma and dendrite signal was slowed significantly. It is possible that this slowing is caused by (1) reduction of a calcium-carrying current by thapsigargin not apparent under control conditions, (2) removal of a rapid calcium release component by thapsigargin, or (3) the delayed onset of the plateau potential seen in the presence of thapsigargin (Fig. $6 B$ ).

Because there was no clear evidence that thapsigargin inhibits calcium current in DLSN neurons, the reduction of calcium increases and the delayed onset associated with ACPD-induced bursting in thapsigargin is most likely through a depletion of internal stores. One possible mechanism is that thapsigargin eliminates the sources of calcium-induced calcium release (CICR). If CICR makes a significant contribution to the total calcium increases associated with ACPD-induced bursting, ryanodine should also cause a reduction of the peak in dendrites of DLSN neurons. We tested ryanodine $(20-100 \mu \mathrm{M})$ in four neurons. Ryanodine consistently caused a sustained elevation of $\left[\mathrm{Ca}^{2+}\right]_{i}$ in soma and dendrites, as demonstrated in Figure $5 C$. It had no detectable effects on the firing of DLSN neurons (Fig. 7A) but clearly impeded the removal of intracellular free calcium (Fig. 7C). Ryanodine also caused a small increase in calcium peaks associated with ACPD-induced burst firing in the dendrites and a small decrease in calcium peaks measured in the soma (Figs. $5 C$, $7 D, 8)$. Neither effect was statistically significant.

In summary, drugs disrupting calcium release from internal stores had only limited effects on calcium increases caused by ACPD-induced bursting in DLSN neurons. The calcium increases in the somata of DLSN neurons may come solely from calcium influx through voltage-gated channels. Our data also suggest that the calcium increases in the dendrites of DLSN neurons are attributable mainly to calcium influx. Finally, these data are inconsistent with the hypothesis that CICR contributes significantly to the calcium increases associated with ACPD-induced bursting.

\section{Measurement of ACPD-induced calcium changes with a low-affinity indicator}

Calcium in DLSN neurons reached very high levels during ACPDinduced bursting. Such increases are possibly too large to be measured by Fura-2, a high-affinity calcium indicator. To obtain a second estimate of the range of calcium increases during ACPDinduced bursting, we injected Mg-Fura-5, a low-affinity indicator (Raju et al., 1989; Petrozzino et al., 1995) into five DLSN neurons. Mg-Fura-5 did not report calcium changes caused by normal firing, because it would only become bound to calcium to a significant degree when $\left[\mathrm{Ca}^{2+}\right]_{\mathrm{i}}$ is $>1 \mu \mathrm{M}$. Calcium changes associated with ACPD-induced bursts are depicted in Figure 9. The spatial and temporal patterns of calcium changes observed with Mg-Fura-5 are similar to those observed with Fura-2. The peak values also show a dose-dependent increase. The peak calcium levels reported during burst firing induced by $20 \mu \mathrm{M}$ 1S,3R-ACPD ranged from 2.7 to $3.8 \mu \mathrm{M}$ in the soma and 4.1 to $8.9 \mu \mathrm{M}$ in the dendrites, with an average of $3.38 \pm 0.21$ and $6.57 \pm 0.72 \mu \mathrm{M}$, respectively. These measurements are higher than values estimated from the Fura-2 signals. Thapsigargin reduced the peaks of dendritic $\left[\mathrm{Ca}^{2+}\right]_{\mathrm{i}}$ caused by ACPD-induced bursting by $20-30 \%$ $(n=2)$. We also observed calcium oscillations in the presence of either ACPD or thapsigargin in two of five DLSN neurons injected with Mg-Fura-5 (data not shown). The amplitudes of these oscillations were in the range of $1-2 \mu \mathrm{M}$. This range is greater than that of oscillations observed with Fura-2.

\section{DISCUSSION}

We and others have demonstrated previously that 1S,3R-ACPD, an agonist for mGluRs, could induce LTP at several CNS synapses. Such an action of ACPD generally has been linked to group I mGluRs, i.e., mGluR1 and 5, which are coupled to PI hydrolysis, and on activation could release calcium from internal stores. Our present data, however, do not support this hypothesis, as it might apply to DLSN neurons. At the concentration range used to induce LTP in various studies (i.e., 10-20 $\mu \mathrm{M}$ ), 1S,3R-ACPD did not elevate $\left[\mathrm{Ca}^{2+}\right]_{\mathrm{i}}$ in most DLSN neurons, which have a very high level of expression of group I mGluRs. On the contrary, ACPD caused a small but significant reduction of $\left[\mathrm{Ca}^{2+}\right]_{i}$ in most of the neurons. Thus, $\mathrm{IP}_{3}$-induced calcium release from internal stores is not likely to play any role in the induction of LTP by ACPD. One feasible alternative is that group I mGluRs activate protein kinase $\mathrm{C}$ (PKC) directly through diacylglycerol and subsequently cause LTP; however, activation of PKC by phorbol esters failed to induce LTP in this preparation (F. Zheng and J. P. Gallagher, unpublished observations).

On the other hand, ACPD dramatically alters the action potential from regular sodium spikes to a burst of sodium spikes on top of a broad plateau potential and elevates intracellular calcium changes associated with firing by six- to sevenfold. We propose that it is this augmentation of activity-driven calcium change that makes the key difference in LTP induction. Our observations suggest that the primary source for the calcium increases is likely transmembrane influx. Neither the endosomal Ca-ATPase inhibitor thapsigargin, which depletes most intracellular stores of calcium, nor ryanodine, which acts on CICR channels, had more than a modest effect on maximum, burst-induced, calcium increases (Figs. 5-8). Furthermore, calcium changes were not augmented by 1S,3R-ACPD during a refractory period of bursting (see Results). These observations suggest that the bulk of calcium goes through the channels underlying the plateau potential.

Channels underlying the ACPD-induced plateau potential are likely located on dendrites, because the pattern of calcium changes observed in this study suggests that calcium changes during ACPD-induced bursting are initiated in dendrites. For example, $\left[\mathrm{Ca}^{2+}\right]_{\mathrm{i}}$ in dendrites reached its peak at the beginning of 


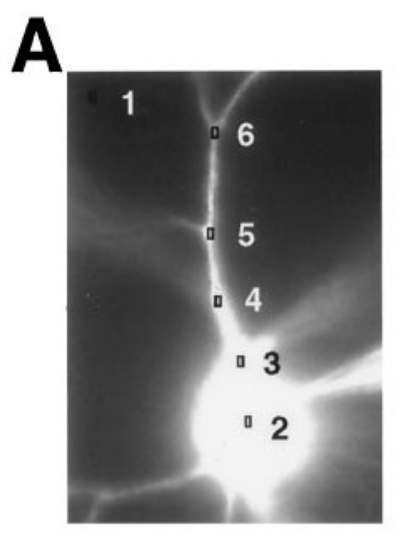

B $10 \mu \mathrm{M} 1 \mathrm{~S}, 3 \mathrm{R}-\mathrm{ACPD}$
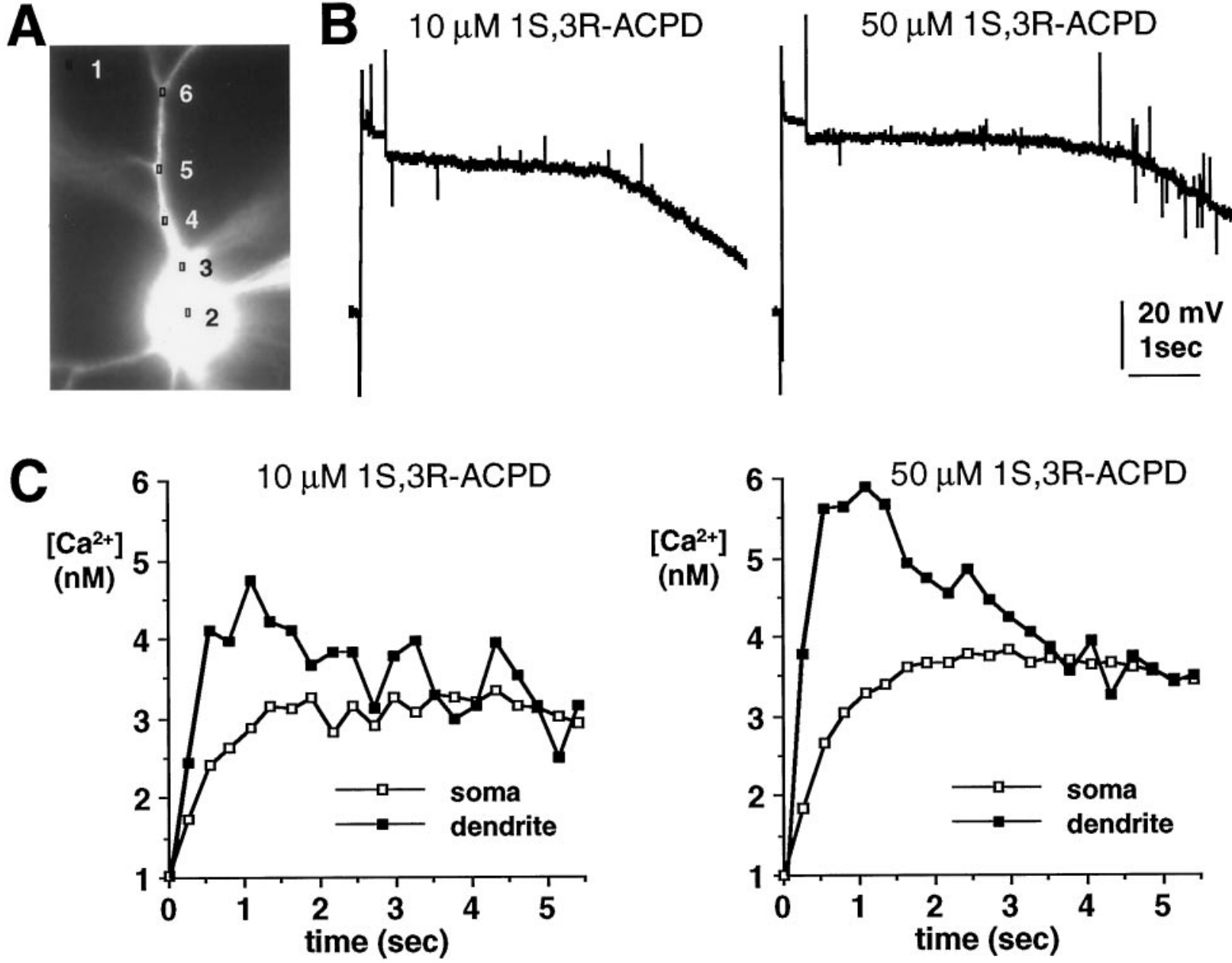

Figure 9. Measurement of calcium increases caused by ACPD-induced bursting with Mg-Fura-5, a low-affinity indicator. $A$, Fluorescence image of neurons $(380 \mathrm{~nm}$ excitation) showing location of measurement boxes $(3 \times 5$ pixels $)$. $B$, Bursting-type action potentials elicited by identical current pulses $(0.25 \mathrm{nA}, 400 \mathrm{msec})$ in 10 and $50 \mu \mathrm{M}$ 1S,3R-ACPD. Membrane potential was held at $-80 \mathrm{mV}$ between action potentials. $C$, Corresponding calcium changes in the soma (box 2) and in the dendrites (an average of box 3-6).

the plateau potential, whereas the changes in calcium levels in the soma lagged behind. Calcium levels in the soma remain elevated when the plateau depolarizing potential has already ended. Although the delay observed in the soma may be attributable to the smaller surface-to-volume ratio in the soma, $\left[\mathrm{Ca}^{2+}\right]_{\mathrm{i}}$ in dendrites is unquestionably far greater than $\left[\mathrm{Ca}^{2+}\right]_{\mathrm{i}}$ in the soma (Fig. $5 A d$ ). The exact identity of those channels remains a mystery. Our observation of a refractory period for ACPD-induced bursting and normal calcium changes during the refractory period suggest that those channels underlying the plateau potential are not calcium channels that are involved in regular firing. Those channels are blocked by nickel and cobalt (Zheng and Gallagher, 1992a). Preliminary data (H. Hasuo, F. Zheng, and J. P. Gallagher, unpublished data) indicate that the channels being potentiated by ACPD are low-threshold, slow-inactivating channels that are not blocked in our slice preparation by any known selective calcium channel blockers that are typically used to characterize calcium channels pharmacologically.

The mechanism of ACPD-induced modulation of the calciumpermeable channels underlying the plateau potentials also remains to be determined. One possibility is that group I mGluRs couple to those channels directly through G-proteins in a membrane-delimited manner. We have demonstrated that
ACPD-induced bursting is mediated by pertussis toxin-sensitive G-proteins (Zheng and Gallagher, 1995b). On the other hand, there is insufficient evidence to show that mGluR5, the only group I mGluRs detected in the septum by immunocytochemistry (Romano et al., 1995), could couple to pertussis toxin-sensitive G-proteins. Thus, the role of group I mGluRs in ACPD-induced LTP is questionable, at least for DLSN neurons.

Although an enhancement of calcium influx by ACPD may have more profound impact than the calcium release from internal stores under our experimental conditions, the effects of ACPD on internal stores could not be ignored. We have observed oscillation of dendritic calcium levels in the presence of either ACPD or thapsigargin. The oscillation of $\left[\mathrm{Ca}^{2+}\right]_{\mathrm{i}}$ occurred without noticeable changes in membrane potentials. The oscillation or increase of $\left[\mathrm{Ca}^{2+}\right]_{\mathrm{i}}$ in these DLSN neurons is likely attributable to calcium release from internal stores, because ACPD caused only a clear reduction in these neurons after they were treated with thapsigargin or other drugs that deplete internal stores (data not shown). Our experimental conditions are not suitable for investigation of this phenomenon. Faster and continuous data acquisitions are required to fully describe this phenomenon. Because we also observed such an oscillation with Mg-Fura-5, dendritic calcium levels could transiently reach several micromoles during the os- 
cillation. The smaller amplitudes of oscillation observed with Fura-2 may be attributable to strong buffering caused by the high-affinity indicator. Such oscillations could not be the underlying mechanism for induction of LTP at DLSN synapses, because thapsigargin did not induce LTP by itself (F. Zheng and J. P. Gallagher, unpublished observations).

We and others have described ACPD-induced inward currents associated with an apparent conductance increase in several brain structures. This type of inward current induced by ACPD is thought to be attributable to activation of CAN channels (Crepel et al., 1994). Our present data demonstrated that an ACPDinduced inward current in most DLSN neurons is associated with a reduction of $\left[\mathrm{Ca}^{2+}\right]_{\mathrm{i}}$. Thus, this current is unlikely to be mediated by CAN channels. The more plausible hypothesis is that the ACPD-induced inward current is attributable at least partially to increased activity of an electrogenic sodium/calcium exchanger, which reduced $\left[\mathrm{Ca}^{2+}\right]_{\mathrm{i}}$. A previous report suggested similarly that the ACPD-induced inward current in cerebellar Purkinje neurons is attributable at least partially to increased activity of an electrogenic calcium pump (Linden et al., 1994).

The huge calcium increases during ACPD-induced bursting could have multiple physiological and pathological implications. This enhanced activity-driven calcium increase is likely to be the underlying mechanism for ACPD-induced LTP in the rat DLSN. Furthermore, it might also be responsible for ACPD-induced neurotoxicity. The rat DLSN is particularly sensitive to $1 \mathrm{~S}, 3 \mathrm{R}$ ACPD. In slice cultures, DLSN neurons were damaged selectively by application of 1S,3R-ACPD (Price et al., 1992). Similar selective damage to the lateral septum was also observed in acute slices when they were treated with 1S,3R-ACPD. This ACPD-induced cell death in the lateral septum is mediated by activation of metabotropic receptors and not by ionotropic receptors (Zheng et al., unpublished observations).

\section{REFERENCES}

Aiba A, Chen C, Herrup K, Rosenmund C, Stevens CF, Tonegawa S (1994a) Reduced hippocampal long-term potentiation and context-specific deficit in associative learning in mGluR1 mutant mice. Cell 79:365-375.

Aiba A, Kano M, Chen C, Stanton ME, Fox GD, Herrup K, Zwingman TA, Tonegawa S (1994b) Deficient cerebellar long-term depression and impaired motor learning in mGluR1 mutant mice. Cell 79:377-388.

Bortolotto ZA, Collingridge GL (1993) Characterisation of LTP induced by the activation of glutamate metabotropic receptors in area CA1 of the hippocampus. Neuropharmacology 32:1-9.

Cha JH, Makowiec RL, Penney JB, Young AB (1990) L- $\left[{ }^{3} \mathrm{H}\right]$ glutamate labels the metabotropic excitatory amino acid receptor in rodent brain. Neurosci Lett 113:78-83.

Collins GG (1994) The characteristics and pharmacology of olfactory cortical LTP induced by theta-burst high frequency stimulation and 1S,3R-ACPD. Neuropharmacology 33:87-95.

Conn PJ, Winder DG, Gereau RW (1994) Regulation of neuronal circuits and animal behavior by metabotropic glutamate receptors. In: The metabotropic glutamate receptors (Conn PJ, Patel J, eds), pp 195-229. Totowa, NJ: Humana.

Crepel V, Aniksztejn L, Ben-Ari Y, Hammond C (1994) Glutamate metabotropic receptors increase a $\mathrm{Ca}^{2+}$-activated nonspecific cationic current in CA1 hippocampal neurons. J Neurophysiol 72:1561-1569.

Gallagher JP, Zheng F, Shinnick-Gallagher P (1994) Long-lasting modulation of synaptic transmission by metabotropic glutamate receptors. In: The metabotropic glutamate receptors (Conn PJ, Patel J, eds), pp 173-193. Totowa, NJ: Humana.

Gallagher JP, Zheng F, Hasuo H, Shinnick-Gallagher P (1995) Activities of neurons within the rat dorsolateral septal nucleus (DLSN). Prog Neurobiol 45:373-395.

Gerber U, Gahweiler BH (1994) Modulation of ionic currents by metabotropic glutamate receptors. In: The metabotropic glutamate receptors (Conn PJ, Patel J, eds), pp 125-146. Totowa, NJ: Humana.
Grynkiewicz G, Poenie M, Tsien RY (1985) A new generation of $\mathrm{Ca}^{2+}$ indicators with greatly improved fluorescence properties. J Biol Chem 260:3440-3450.

Hasuo H, Phelan KD, Twery MJ, Gallagher JP (1990) A calciumdependent slow afterdepolarization recorded in rat dorsolateral septal nucleus neurons in vitro. J Neurophysiol 64:1838-1846.

Jaffe DB, Brown TH (1994) Metabotropic glutamate receptor activation induces calcium waves within hippocampal dendrites. J Neurophysiol 72:471-474.

Linden DJ, Smeyne M, Connor JA (1994) Trans-ACPD, a metabotropic receptor agonist, produces calcium mobilization and an inward current in cultured cerebellar Purkinje neurons. J Neurophysiol 71:1992-1998.

Markram H, Helm PJ, Sakmann B (1995) Dendritic calcium transients evoked by single back-propagating action potentials in rat neocortical pyramidal neurons. J Physiol (Lond) 485:1-20.

Nelson EJ, Li CC, Bangalore R, Benson T, Kass RS, Hinkle PM (1994) Inhibition of L-type calcium-channel activity by thapsigargin and 2,5-tbutylhydroquinone, but not by cyclopiazonic acid. Biochem J 302: 147-154.

Petrozzino JJ, Pozzo Miller LD, Connor JA (1995) Micromolar $\mathrm{Ca}^{2+}$ transients in dendritic spines of hippocampal pyramidal neurons in brain slice. Neuron 14:1223-1231.

Pin JP, Duvoisin R (1995) Neurotransmitter receptor I. The metabotropic glutamate receptors: structure and functions. Neuropharmacology 34:1-26.

Price MT, Ikonomidou C, Labruyere J, Izumi Y, Olney JW (1992) Neurotoxicity linked to the glutamate metabotropic receptor. Soc Neurosci Abstr 18:83.

Raju B, Murphy E, Levy LA, Hall RD, London RE (1989) A fluorescent indicator for measuring cytosolic free magnesium. Am J Physiol 256:540-548.

Romano C, Sesma MA, McDonald CT, O'Malley K, van den Pol AN, Olney JW (1995) Distribution of metabotropic glutamate receptor mGluR5 immunoreactivity in rat brain. J Comp Neurol 355:455-469.

Shmigol A, Kostyuk P, Verkhrasky A (1995) Dual action of thapsigargin on calcium mobilization in sensory neurons: inhibition of $\mathrm{Ca}^{2+}$ uptake by caffeine-sensitive pools and blockade of plasmalemmal $\mathrm{Ca}^{2+}$ channels. Neuroscience 65:1109-1118.

Stevens DR, Gallagher JP, Shinnick-Gallagher P (1984) Intracellular recordings from rat dorsolateral septal neurons, in vitro. Brain Res 305:353-356.

Thastrup O, Cullen PJ, Drobak BK, Hanley MR, Dawson AP (1990) Thapsigargin, a tumour promotor, discharges intracellular $\mathrm{Ca}^{2+}$ stores by specific inhibition of the endoplasmic reticulum $\mathrm{Ca}^{2+}$-ATPase. Proc Natl Acad Sci USA 87:2466-2470.

Tsien RY, Poenie M (1986) Fluorescence ratio imaging: a new window into intracellular ionic signalling. Trends Biochem Sci 11:450-455.

Zheng F, Gallagher JP (1991) Trans-ACPD (trans-D,L-1-amino-1,3cyclopentane-dicarboxylic acid) elicited oscillation of membrane potentials in rat dorsolateral septal nucleus neurons recorded intracellularly in vitro. Neurosci Lett 125:147-150.

Zheng F, Gallagher JP (1992a) Burst firing of rat septal neurons induced by $1 \mathrm{~S}, 3 \mathrm{R}-\mathrm{ACPD}$ requires influx of extracellular calcium. Eur J Pharmacol 211:281-282.

Zheng F, Gallagher JP (1992b) Metabotropic glutamate receptor agonists potentiate a slow afterdepolarization in CNS neurons. NeuroReport 3:622-624.

Zheng F, Gallagher JP (1992c) Metabotropic glutamate receptors are required for the induction of long-term potentiation. Neuron 9:163-172.

Zheng F, Gallagher JP (1992d) Calcium release from internal stores is required for the met-GluR-dependent LTP in DLSN neurons in vitro. Soc Neurosci Abstr 18:642.

Zheng F, Gallagher JP (1995a) Pharmacologically distinct, pertussis toxin-resistant inward currents evoked by metabotropic glutamate receptor (mGluR) agonists in rat dorsolateral septal nucleus neurons. J Neurosci 15:504-510.

Zheng F, Gallagher JP (1995b) A native pertussis toxin-sensitive metabotropic glutamate receptor at rat dorsolateral septal nucleus. Neuroscience 68:423-434.

Zheng F, Lonart G, Johnson KM, Gallagher JP (1994) (1S,3R)-1aminocyclopentane-1,3-dicarboxylic acid (1S,3R-ACPD) induced burst firing via an inositol-1,4,5-triphosphate-independent pathway at rat dorsolateral septal nucleus. Neuropharmacology 33:97-102.

Zirpel L, Lachica EA, Rubel EW (1995) Activation of a metabotropic glutamate receptor increases intracellular calcium concentrations in neurons of the avian cochlear nucleus. J Neurosci 15:214-222. 